\title{
The Use of QIin the Pre-Qin Period of China: A Corpus-Based Study
}

\author{
Changrong Li \& Hongkun Li \\ Foreign Studies College \\ Hunan Normal University \\ Changsha, China
}

\begin{abstract}
QI (air) is one of the key concepts throughout the development of Chinese traditional philosophy and culture. This study explores the thought of QI in the pre-Qin period of China by a corpus-based quantitative study of the meanings of QI in the scriptures of this period. Results show that a majority of the meanings of QI have been produced in the pre-Qin period and there is a priority list of scriptures in terms of the contributions of the meaning extension of QI. The period of the Spring and Autumn and Warrior States (a period before Qin Dynasty) is an important stage when QI was used extensively and many philosophical thoughts related to QI were produced.
\end{abstract}

Key words: the thought of QI, pre-Qin histories, scriptures, corpus-based

\section{Introduction}

In Chinese traditional philosophy, “QI(气, air)” is one of the most important concepts in the formation of Chinese traditional culture and philosophy. The character QI first appeared on the tortoise shells in the Shang Dynasty(1600BC-1046BC)which were used, to a large extent, to record the traits of clouds so as to predict people's daily chances of fortune. Since the Zhou Dynasty (1046BC-771BC) QI has been used as a philosophical concept to explore the origins of the universe. Its meaning was then largely extended in the Spring and Autumn and Warrior States(春秋战国 770BC-221BC) and has since had great influences on the course of Chinese traditional culture and philosophy (Li Cunshan, 1990). Take Traditional Chinese Medicine (TCM)as an example. InHuang Di Nei Jing (《黄 帝内经》), the Chinese earliest medical book which is thought to have been written in the Warrior States and to have set the foundation of TCM, QI appeared as many as 2,987 times out of the 157,680 character sand was used as the key concept in physiology, pathology, and therapy of the human body, from which many QI-based TCM thoughts were produced, including gxueqi (血气), qifu(气府), zangqi(藏气), etc.

QI has been used as a philosophical concept in the pre-Qin period, but the previous studies of QI of that period mostly concentrated on the following three aspects: the philosophical origins of "QI Monism" theory", the philosophical connotations of QI, and its contributions to Chinese traditional philosophy (Li Cunshan, 2006, 2012). There are a few studies discussing the influence of QI on other areas such as literature (Chu Xiaoying, 2007), Sports (Zhang Rongming, 2011), TCM (Wang Yuxing, 1996; Wang Lei et al, 2012), and culture (Zhang Yuanhua, 1993) etc., but they are not the mainstream studies of QI of the pre-Qin period.

Pre-Qin period is an important stage for the increase in the number of Chinese characters and their meanings. But, to the authors' best knowledge, there were very few researches investigating the meanings of QIof that period from a linguistic perspective. Huang analyzed the meanings of QI from the structures of the character used in the documents of the pre-Qin histories (On the Chinese Character QI 96). Qu(2014) made a tentative study of the meanings and the cultural connotations of QI. In Qu's study, she first extracted 12 meaning items of QI that are thought by her to have been used in the pre-Qin histories, but her extraction was based on analysis of the examples given to illustrate the meanings of QI income mainstream Chinese dictionaries such as Kang Xi Zi Dian( 《康熙字典》, a 42-volume Chinese dictionary compiled during the reign of Kang Xi in the Qing Dynasty), Ci Yuan(《辞源》), and Han Yu Da Ci Dian(《汉 语大词典》, the Chinese Dictionary), etc (3). 
This way of meaning extraction may lead to incomplete meaning coverage for the examples used by a dictionary to illustrate the meaning of a word is to a large extent limited and it is very likely that there are more meanings of QI used by people of the pre-Qin histories than what is covered in the dictionaries. If there are more than 12 meaning items of QI used in the pre-Qin histories, then the whole follow-on work made by Qu should be redirected. Another problem that may distort Qu's study is her choice of the 12 famous scriptures. Only 12 scriptures were selected among the numerous works written in the long pre-Qin histories. The scriptures were too limited to cover a comprehensive study of the meaning extensions of QI because a lot of sentences that convey QI in other scriptures may be rejected by her subjectively. One principle applied by Qu to select these scriptures is the frequency of QI used in the scriptures. But in Analects of Confucius (论语), a scripture selected by Qu for analysis, QI was used only 6 times. As a matter of fact, some important scriptures of the pre-Qin histories in which QI was much more frequently used were subjectively rejected by her, such as Lu Shih Chun Chiu (吕氏春秋) and Book of Rites (礼记) in which QI was used 97 times and 69 times respectively. The reason that $\mathrm{Qu}$ did not count in these scriptures with high frequency of QI uses may be that she did not think these were important scriptures that have made great contributions to the development of the meanings and cultural connotations of QI, another very subjective principle applied by her to select the scriptures.

QI in modern Chinese language is a high frequency word with wide meaning extensions. In Han Yu Da Ci Dian $\left(1986^{2}\right)$, one of the most authoritative dictionaries of Chinese, the meanings of QI reach 33 items except its extensive phrasal uses. A word may carry with it rich philosophical and cultural thoughts of the people who use it, as cited by one of the famous masters of Chinese culture: "The traces of the changes of nature in remote ages or the deeds of emperors of middle ancient times can hardly be found in biographical documents, but they are stored in the words and in between the lines of the language.”“上世草味，中古帝王之行事，存于传记者已塞，惟文字、语言间留其痕 迹。”Wan Xianchu, 35)As QI has already been used as a philosophical concept in the pre-Qin histories, and as philosophical thoughts are conveyed in the form of language, we need to provide a quantitative study on QI based on corpus data of the scriptures that used QI in a written form of the language of that period, so as to get a quantitative overview of the meanings and the detailed semantic features of QI which may help us have a more objective understanding of the cultural and philosophical origination of QI from its various usage in scriptures and thus help strengthen the cultural confidence of Chinese people.

\section{Research Methodology}

\subsection{Research questions}

This study intends to answer the following 3 questions:

1) What pre-Qin scriptures in CN Corpus have used QI? What are their contributions in meaning extension of QI in terms of frequency?

2) What meanings of QI appear in these scriptures? How are they distributed in these scriptures?

3) What collocates of QI ar eused in these scriptures? What are the semantic features of these collocates?

The first question is to observe the frequencies of QI and its meaning items used in each pre-Qin scripture in the CN Corpus, so that we can find out those scriptures that have made more contributions than others in the spread of a specific meaning of QI. To answer this question, a large corpus that incorporates as many scriptures of the pre-Qin histories as possible is needed. The second question is to look into the frequencies of the original and extended meaning items of QI so that we can sort out those meaning items that stand out among all the meaning items of QI used in the pre-Qin period, which may predict the development trend of QI as a cultural and philosophical concept. The third question is to determine what words in the pre-Qin histories have collocated with QI by analyzing those characters that appear immediately before and after QI.

\subsection{Research instruments}


The present study is a CN Corpus based quantitative observation of QI used in various scriptures of the pre-Qin histories and it aims at making an objective and comprehensive analysis of the meanings of QI used in that period of time. These collocated words will be further analyzed in terms of semantic preferences so that we can find what words often co-occur with QI and what semantic features these preferentially collocated words reveal about QI. Besides, these collocates will be testified by the phrases of QI collected by Han Yu Da Ci Dian (《汉语大辞典》1986) to check what collocates have become fixed phrases since then and to differentiate their meanings with those used today. To answer these questions, a meaning set that contains almost all the meanings of QI in history should be built first so that they can be referred to as a parameter when judging the meaning of QI in each concordance line extracted from the corpus.

\subsection{Research procedure}

The first step of this study is to find an appropriate corpus for data collection of QI. By comparing the popular Chinese corpora, we chose $\mathrm{CN}$ Corpus $^{3}$ which provides online search services for data collection. It is a corpus that contains almost all the scriptures of Complete Library in Four Branches of Literature (《四库全书》), the largest collection of classic ancient works of China handed down till mid-Qing Dynasty, which means that nearly all classic ancient works were collected in this corpus. As a result, it is very likely that QI concordance from this corpus has a greater variety of scriptures than from any other corpus. And we can search the corpus based on the dynasties from the Zhou Dynasty(1046BC-771BC) on, which helps us quickly locate the data set of pre-Qin period. Another advantage of this corpus as compared with other Chinese corpora is that it provides the scripture source for each concordance line, which helps to collect data of QIused in respective scriptures ${ }^{4}$. With the given corpus at hand, we input the Chinese character QI (both in modern simplified and traditional forms) and selected in the dynasty list the Zhou Dynasty and the Spring and Autumn and Warrior States Period separately and altogether got a downloadable data set of 737 concordance lines. Then these lines were downloaded for meaning classification of QI.

In order to locate the meaning of each concordance line of QI, we built a meaning set for QI based on the meaning expositions of QI in the dictionary Han Yu Da Ci Dian (1986). The reason for choosing this dictionary to build the set is that it is generally acknowledged that this dictionary contains the most comprehensive meaning items and collocation items of a single Chinese character, including those used in ancient as well as in modern times. Another reason is that there are many examples quoted directly without modification from the ancient documents to illustrate each meaning item, which provides good context for the sense item to be understood. Based on these meaning items, the present study built a 31-item meaning set for QI. This set excludes the senses in the dictionary that QI is used as "provisions for troop" and as a replacement character for other not yet created characters as they have no relation to the present study. The senses in the set were then grouped into 3 categories: the original meaning, the general extended meanings, and the philosophical meanings. According to Shuo Wen JieZi (《说文解字》), the first Chinese dictionary and the most influential dictionary of classical Chinese compiled by XuShen (121AD), the original meaning of QI is "floating clouds (云气)", and the other meanings are extended from this original meaning. In this study, the extended meanings of QI are further classified into general extended and philosophical because in China QI has long been regarded as a philosophical concept to refer to the substance that constitutes the universe and human body, which should be differentiated from the generally extended meanings of QI. The senses and the categories they belong to are shown in Table 1: 
Table 1: The meaning set of QI

\begin{tabular}{|c|c|c|}
\hline $\begin{array}{l}\text { Original } \\
\text { meaning }\end{array}$ & General extended meanings & Philosophical meanings \\
\hline $\begin{array}{l}\text { 1. floating } \\
\text { clouds(云气) }\end{array}$ & $\begin{array}{l}\text { 2.air(空气) 3.breath(气息、呼吸) 4.climate(节气、 } \\
\text { 气候)5.weather(气象)6.manner of speaking(语气、 } \\
\text { 声气 ) 7.personal behavior( 作 风、习气 } \\
\text { 8.feelings(精神状态、情绪) 9.anger(气恼、生 } \\
\text { 气)10.attribute(人、物属性或一地天然特点) } \\
\text { 11.odor(气味) 12.arrogance(气焰、权势) 13.mood } \\
\text { of society(社会风气、习俗) 14.atmosphere(气氛、 } \\
\text { 景象) 15.look of great force(气派、气概、气 } \\
\text { 势)16.personal loyalty(义气) 17.complexion(气 } \\
\text { 色、表情) 18.effect(效力、作用)19.mirage(蜃气) } \\
\text { 20.fate(气运) 21.to make sb angry(使人生气) 22.to } \\
\text { bully(欺压) 23.style of a writer(作家气质或作品 } \\
\text { 风格) 24.Qigong(气功) 25.quantifier(量动词) } \\
\text { 26.to smell(闻、嗅) }\end{array}$ & $\begin{array}{l}\text { 27.primitive substance } \\
\text { by naive materialism(物 } \\
\text { 质本原) } \\
\text { 28.subjective mind by } \\
\text { objective idealism(主观 } \\
\text { 精神) } \\
\text { 29.QI-blood(血气) } \\
\text { 30.meridian-QI( 中医脉 } \\
\text { 气和营卫及病象) } \\
\text { 31.substance defined by } \\
\text { Neo-Confucianism(理之 } \\
\text { 后的物质) }\end{array}$ \\
\hline
\end{tabular}

With the meaning set at hand, the concordance lines of QI from the CNCorpus were applied to the KWIC-based Annotation Tool for judgment of the meaning of QI in each concordance line. The KWIC-based Annotation Tool is a semi-automatic tool designed and developed by BFSU Corpus Research Group to help judge the meaning of a polysemy by analyzing the contexts before and after the polysemous word. If the same word under analytical consideration in different concordance lines appears to have similar contexts, then the tool will input the same meaning automatically in other lines after we input the meaning in the first line. This helps us to make judgments objectively and with accuracy. Besides, this tool stores automatically the concordance lines with the same meaning of the searched word in separate files. Data analyses in this research were done with SPSS22.0.

\section{Data analysis and discussion}

\subsection{QI used in the scriptures of the CNCorpus}

Altogether 737 lines were trawled from the online CNCorpus by the searching character QI (with modern simplified and traditional forms). Six lines were deleted because QI in these lines was used either as a replacement character for other characters (4 lines) or provisions for troop (2 lines). The remaining 731 lines were classified into different groups according to their scriptures they come from. The scriptures and the number of lines that used QI in each scripture are displayed in Table 2. 
Table 2: Scriptures and number of lines of QI in each scripture in the CNCorpus

\begin{tabular}{llllll}
\hline Scripture & Lu Shi Chun Chiu & Book of Rites & Yi Zhou Shu & Chuang Tzu & Lieh Tzu \\
\hline No of QI & 97 & 67 & 66 & 46 & 44 \\
\hline Scripture & Ho Kuan Tzu & Notes of Lao Tzu & The Odes of Chu & Book of Changes & The Yin Fu Seven \\
\hline No of QI & 42 & 32 & 31 & 26 & 22 \\
\hline Scripture & Sun Bin's Art of War & Kuei Ku-tzu & Guo Yu & Xun Tzu & Guan Tzu \\
\hline No of QI & 23 & 23 & 22 & 22 & 21 \\
\hline Scripture & The Mencius & TsoChuan & The Chou Rituals & Liu Tao & The Weiliaozi \\
\hline No of QI & 20 & 18 & 18 & 16 & 12 \\
\hline Scripture & The Art of War & Yen Tzu Chun Chiu & Fan ZiJi Ran & Analects of Confucius & Mo Tzu \\
\hline No of QI & 12 & 9 & 7 & 6 & 5 \\
\hline scripture & Yinfujing & Classic of Mountains & Methods of Sima & Book of Lord Shang & The Etiquettes \\
\hline No of QI & 5 & 4 & 4 & 3 & 3 \\
\hline Scripture & Lao Tzu & Book of Elocutionist & Woqijing & & \\
\hline No of QI & 2 & 1 & 1 & & \\
\hline
\end{tabular}

As shown in Table 2, in the CNCorpus, QI is found in 33 scriptures of the pre-Qin period, taking up to $82.5 \%$ of all the scriptures of that period of time collected by the corpus (the total number of classic scriptures of pre-Qin histories collected by the corpus is 40). The high percentage demonstrates that QI has become a widely used character in pre-Qin documents.

But it was not normally distributed. QI in Lu Shi Chun Chiu (《吕氏春秋》) appeared 97 times, while in Book of Elocutionist (《纵横家书》) and Woqijing (《握奇经》) it was used only once separately, which may be a sign that there are books in the pre-Qin histories that have greater contributions in use of QI. The Euclidean 3-hierarchy cluster analysis was applied to sort out those scriptures that stand out in frequency of use of QI. The results are shown in Figure 1.

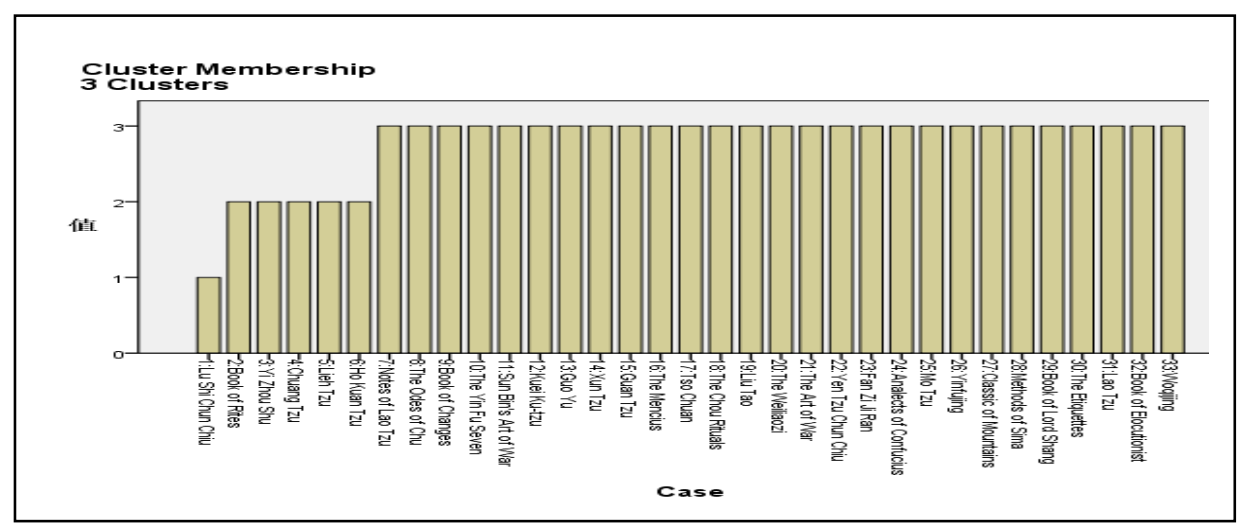

Figure 1: Clusters of scriptures with regard to frequencies of QI

The results in Figure 1 show that only one scripture which is Lu Shi Chun Chiu falls into cluster 1, which may be regarded as level 1 importance in the use of QI in terms of frequency in the corpus. In cluster 2, there are 5 scriptures, namely Ho Kuan Tzu (《鹖冠子》), Yi Zhou Shu (《逸周书》), Chuang Tzu (《庄子》), Lieh Tzu( 《列子》), and Book of Rites(《礼记》), which ranks as level 2 importance. The scriptures in cluster 3 belong to the third level. Besides the frequency of the use of QI, the sense items in each scripture should also be considered because this is an important indicator to assess the degree to which the meanings of QI are spread in individual scripture. With the help of the 
KWIC-based Annotation Tool, we selected, according to the contexts, one meaning from the meaning set of QI for each concordance line, and got a folder of 22 files in which 731 concordance lines were stored separately with those of the same meaning in the same file. The lines in each scripture with the same meaning were then classified as one meaning item and the meaning items were counted for each scripture. The results are shown in Table 3.

Table 3: Scriptures and number of meaning items of QI in each scripture in the CNCorpus

\begin{tabular}{|c|c|c|c|c|c|}
\hline Scripture & Lu Shi Chun Chiu & Book of Rites & Yi Zhou Shu & Chuang Tzu & Lieh Tzu \\
\hline Sense items & 11 & 13 & 10 & 11 & 6 \\
\hline Scripture & Ho Kuan Tzu & Notes of Lao Tzu & The Odes of Chu & Book of Changes & The Yin Fu Seven \\
\hline Sense items & 6 & 6 & 13 & 3 & 2 \\
\hline Scripture & Sun Bin's Art of War & Kuei Ku-tzu & Guo Yu & Xun Tzu & Guan Tzu \\
\hline Sense items & 1 & 4 & 6 & 6 & 4 \\
\hline Scripture & The Mencius & TsoChuan & $\begin{array}{l}\text { The Chou } \\
\text { Rituals }\end{array}$ & Liu Tao & The Weiliaozi \\
\hline Sense items & 2 & 6 & 5 & 4 & 1 \\
\hline Scripture & The Art of War & Yen Tzu Chun Chiu & Fan ZiJi Ran & $\begin{array}{l}\text { Analects of } \\
\text { Confucius }\end{array}$ & Mo Tzu \\
\hline Sense items & 2 & 7 & 2 & 3 & 4 \\
\hline scripture & Yinfujing & Classic of Mountains & Methods of Sima & Book of Lord Shang & The Etiquettes \\
\hline Sense items & 2 & 2 & 1 & 2 & 1 \\
\hline Scripture & Lao Tzu & Book of Elocutionist & Woqijing & & \\
\hline Sense items & 2 & 1 & 1 & & \\
\hline
\end{tabular}

The numbers of meaning items were then run with Euclidean 3-hierarchy cluster analysis to sort out those scriptures that stand out in terms of the frequency of meaning items of QI. The results are shown in Figure 2

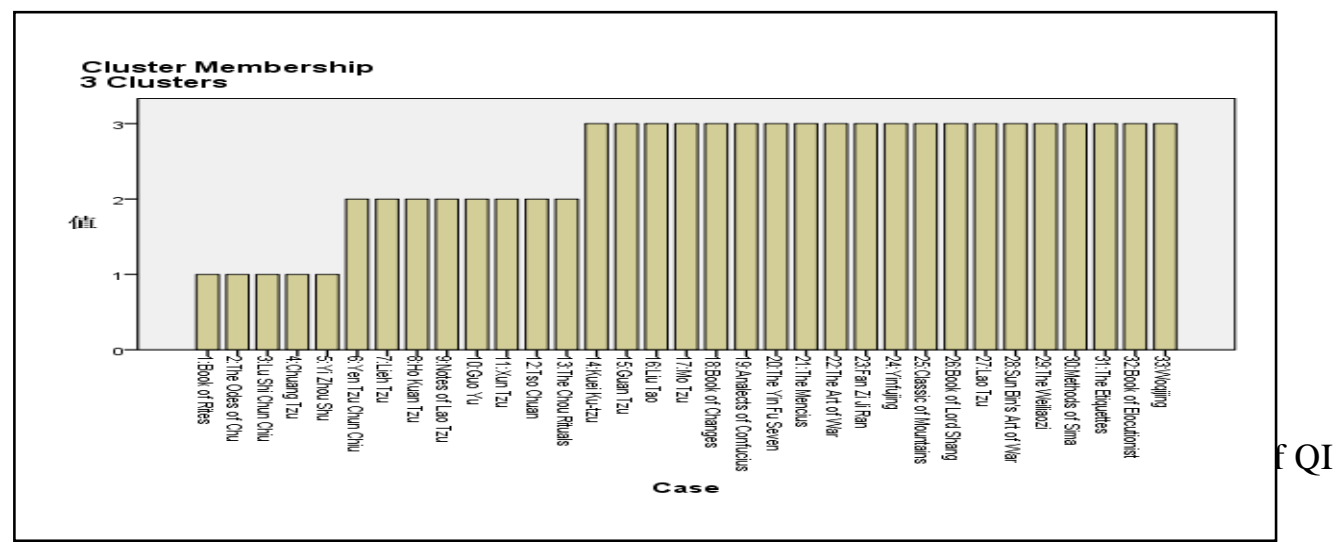

The results in Figure 2show that there are 5 scriptures in the CN Corpus, namely Book of Rites, The Odes of Chu(《楚 辞〉), Lu Shi Chun Chiu, Chuang Tzu, Yi Zhou Shu, which rank as level 1 importance in the use of QI in terms of the numbers of the meaning items in the corpus. In cluster 2, there are 8 scriptures, namely Yen Tzu Chun Chiu (《晏子 春秋》), Lieh Tzu, Ho Kuan Tzu, Notes of Lao Tzu (《老子想尔注》), Guo Yu( 《国语》), Xun Tzu(《荀子》), TsoChuan (《左传》), and The Chou Rituals (《周礼》), which rank as the second level. And the scriptures in cluster 3 belong to the third level.

As a result, the scriptures in the CN Corpus can be distributed into 5 levels in terms of the contributions they have made about the use of QI by taking into consideration both frequencies of use and frequencies of meaning items of QI in each scripture. If the scripture falls into the first clusters of both frequency analyses, this scripture is labeled as level 1 in terms of contributions. If it falls into either of cluster one, it is labeled as level 2. If it falls into the second 
clusters of both frequency analyses, then it is labeled as level 3. If it falls into either of the second cluster, then it is labeled as level 4. For those who fall into both cluster 3, they are labeled level 5. The classification results are shown in Table 4.

Table 4: Distributions of scriptures in terms of contributions in use of QI in the CNCorpus

\begin{tabular}{|l|l|l|l|l|}
\hline Level 1 & Level 2 & Level 3 & Level 4 & Level 5 \\
\hline $\begin{array}{l}\text { Lu Shi } \\
\text { Chun } \\
\text { Chiu }\end{array}$ & $\begin{array}{l}\text { Book of Rites, } \\
\text { Yi Zhou Shu, } \\
\text { The Odes of } \\
\text { Chu, } \\
\text { Chuang Tzu }\end{array}$ & $\begin{array}{l}\text { Lieh Tzu, } \\
\text { Ho Kuan } \\
\text { Tzu, }\end{array}$ & $\begin{array}{l}\text { Notes of Lao Tzu, } \\
\text { Guo Yu, } \\
\text { Xun Tzu, } \\
\text { TsoChuan, } \\
\text { Yen Tzu Chun Chiu, } \\
\text { The Chou Rituals }\end{array}$ & $\begin{array}{l}\text { Book of Changes, The Yin Fu Seven, Sun } \\
\text { Bin's Art of War, Kuei Ku-tzu, Guan Tzu, } \\
\text { The Mencius, The Chou Rituals, Liu Tao, } \\
\text { The Weiliaozi, The Art of War, Fan ZiJi Ran, } \\
\text { Analects of Confucius, Mo Tzu, Yinfujing, } \\
\text { Classic of Mountains, Methods of Sima, } \\
\text { Book of Lord Shang, The Etiquettes, Lao } \\
\text { Tzu, Book of Elocutionist, Woqijing }\end{array}$ \\
\hline
\end{tabular}

This hierarchy provides a priority list (without taking into account of Huang Di Nei Jing) for people of today to look into the origins of QI as a cultural and philosophical concept in China. From this hierarchy, Lu Shi Chun Chiu is the first book to refer to by people to trace the origins of QI.

\subsection{Meaning distribution features of QI in pre-Qin scriptures}

In order to get the meaning distribution features of QI in the pre-Qin scriptures, we calculated the number of hits in each sense file in accordance with the meaning classification of QI in Table 1. The results are shown in Table 5 with the number of hits for each meaning and the total number of hits for each category displayed in brackets.

Table 5: Number of hits for each meaning of QI and the total number for each sense category

\begin{tabular}{|c|c|c|c|c|c|}
\hline \multirow{2}{*}{$\begin{array}{l}\text { Original meaning(13) } \\
\text { General extended } \\
\text { meanings(347) }\end{array}$} & \multicolumn{5}{|l|}{ floating clouds } \\
\hline & $\begin{array}{l}\text { air } \\
(91)\end{array}$ & $\begin{array}{l}\text { breath } \\
(30)\end{array}$ & $\begin{array}{l}\text { climate } \\
(31)\end{array}$ & $\begin{array}{l}\text { odor } \\
\text { (13) }\end{array}$ & $\begin{array}{l}\text { arrogance } \\
\text { (1) }\end{array}$ \\
\hline & $\begin{array}{l}\text { feelings } \\
(122)\end{array}$ & $\begin{array}{l}\text { attribute } \\
(9)\end{array}$ & $\begin{array}{l}\text { weather } \\
\text { (9) }\end{array}$ & $\begin{array}{l}\text { atmosphere } \\
\text { (3) }\end{array}$ & $\begin{array}{l}\text { personal } \\
\text { behavior } \\
\text { (3) }\end{array}$ \\
\hline & $\begin{array}{l}\text { personal loyalty } \\
\text { (2) }\end{array}$ & $\begin{array}{l}\text { anger } \\
(2)\end{array}$ & $\begin{array}{l}\text { complexion } \\
\text { (1) }\end{array}$ & $\begin{array}{l}\text { to smell } \\
(2)\end{array}$ & $\begin{array}{l}\text { mood of } \\
\text { society } \\
(13)\end{array}$ \\
\hline & $\begin{array}{l}\text { look of great force } \\
\text { (11) }\end{array}$ & \multicolumn{4}{|c|}{$\begin{array}{l}\text { manner of speaking } \\
(4)\end{array}$} \\
\hline $\begin{array}{l}\text { Philosophical } \\
\text { meanings( } 371)\end{array}$ & $\begin{array}{l}\text { primitive } \\
\text { substance by naive } \\
\text { materialism(211) }\end{array}$ & $\begin{array}{l}\text { QI-blood } \\
(63)\end{array}$ & $\begin{array}{l}\text { meridian-QI } \\
\text { (71) }\end{array}$ & \multicolumn{2}{|c|}{$\begin{array}{l}\text { subjective mind by objective } \\
\text { idealism } \\
(26)\end{array}$} \\
\hline
\end{tabular}

The results in Table 5 show that 22 out of 31 meanings of QI have been used in the pre-Qin histories, which means that $2 / 3$ rds of the meanings of QI have appeared in the pre-Qin period. This result plus the high percentage of scriptures (33 out of 40 in the CNCorpus) in which QI has been used indicates that QI in the pre-Qin period has become a very active word with its various meaning used to explore the origins of nature and human beings.

The total number for each sense category shows that QI in pre-Qin period has been used almost absolutely with its 
extended meanings, and among the extended meanings, more than one half of QI was used as a primitive substance that constitutes the world and human body. The high percentage of QI used as a primitive substance indicates that QI has been highly abstracted as a philosophical concept by people of the pre-Qin period to help understand the origins of the world and everything in the world including human beings. This claim can be further strengthened by the fact that in the pre-Qin period 4 more subtle substances have been elaborated out of "Yin Yang" which was originally used to generally refer to the primitive substance: "Jingqi (vital essence)", "Wuxing (QI of five elements)", "Xueqi (QI-blood)", and "Yuanqi (primordial QI)". Although there are not many lines in which QI is used with these subtle meaning (Jingqi for 16 hits, Wuxing for 12 hits, and Yuanqi for 2 hits), it is sufficient to show that people in the pre-Qin period began to think about the different substances that constitute the world, and this trend laid the foundation for the development of QI as a cultural and philosophical concept in China.

An interesting finding is that, when looking into the sense "Yin Yang" the most frequently used meaning (181 hits) among the scriptures, four scriptures stand out by their apparently higher frequency of this meaning than the other scriptures:

Ho Kuan Tzu (35 hits), Lu Shi Chun Chiu (21 hits), Lieh Tzu (19 hits), and Chuang Tzu (19 hits). What's interesting is that these four books fall into the same school of philosophical thought: the Daoism, one of the most influential Chinese traditional philosophy. Consequently, these four books become the first priority for people who are interested in exploring the origins of Daoism after Lao Tzu, founder of Daoism.

In the general extended senses category, six meanings, namely "air, climate, weather, breath, odor, and to smell", can be subdivided into the concrete meaning group because these meanings reflect the air in nature as well as its performance like cold / hot and wind / rain etc. and the air that people breathe and smell. The other 11 meaning in this category fall into the abstract meaning group for they are mainly used to refer to such abstract concepts like human character and social phenomena. The meanings in these two subdivided groups and their total hits are displayed in Table 6.

Table 6: Concrete vs. abstract senses in the general extended meaning category

\begin{tabular}{|c|c|c|c|}
\hline \multicolumn{2}{|c|}{ Concrete } & \multicolumn{2}{|l|}{ Abstract } \\
\hline meaning & $\begin{array}{c}\text { Total } \\
\text { hits }\end{array}$ & meaning & $\begin{array}{c}\text { Total } \\
\text { hits }\end{array}$ \\
\hline $\begin{array}{l}\text { air(91),climate(31), } \\
\text { weather(9), } \\
\text { breath(30), } \\
\text { odor(13),to smell(2) }\end{array}$ & 176 & $\begin{array}{l}\text { feelings(122), anger (2), } \begin{array}{r}\text { personal } \\
\text { behavior(3), }\end{array} \text { personal } \\
\text { arrogance(1), manner of } \\
\text { complexion(1), attribute(9), atmosphere(3), } \\
\text { mood of society(13), look of great force(11) }\end{array}$ & 171 \\
\hline
\end{tabular}

It is apparent from Table 6 that the concrete and abstract meanings of QI in the CNCorpus are almost evenly distributed in terms of frequency. But as a matter of fact, among the abstract meanings the "feelings" meaning is used more frequently than the others. Consequently, the frequencies of most abstract meaning items are very low, except the "feelings" which is mostly used in the scriptures about tactics of war to refer to the morale of troops.

The difference between the high frequency use of the "feelings" and the low frequencies of the other abstract meaning may well indicate that QI began to be used by people to explore human nature and in social life in the pre-Qin period but their exploration was mainly focused on human feelings. One meaning that deserves special attention is "anger" which to a certain degree belongs to feelings. In modern Chinese, QI has almost been grammaticalized to refer to anger when it is used as a single word, but the data in this corpus show that there are only two hits that convey the meaning of anger. 


\subsection{The collocates of QI in pre-Qin scriptures}

The work prior to this section of this study is mainly focused on the priority tendencies of the scriptures in the use of QI and the meanings from the character itself without investigating into its collocation. It is necessary for this study to look further into how QI was used with other words by analyzing those words that appear immediately before and after QI, so as to find its semantic preferences. This work was done by applying the corpus concordance software AntConc 3.5.0 developed by Laurence Anthony of Waseda University Japan.

A common technical problem when analyzing Chinese language with AntConcis that there is no space among characters within a sentence, andit is impossible to use the tool to segment words in Chinese since it depends on the space when judging whether a character or group of characters is a word or not. In order to identify the collocates of QIwith AntConc, we manually segmented the first word that appears before and after QI of each concordance line before they were fed into the software for computing. Then the collocates of QI were searched by conditions with the window size set "from $1 \mathrm{~L}$ to $0 \mathrm{R}$ " and "from $0 \mathrm{~L}$ to $1 \mathrm{R}$ " separately.

The collocates from the left and right side of QI were stored in respective files and they were inspected to delete such words as empty or interference words for they are not the true collates of QI. Finally, we got two separated collocate lists of QI with 156 word types on its left side and 138 on its right side.

On the one hand, judging from the number of word types on both sides, there is no significant difference on whether QI was collocated with more words on the left side or more on the right side in the pre-Qin period. But when these word types are grouped, based on their frequency of occurrence, into 5 sets with those occurring more than 10 times and those occurring only once in two separate sets and those in the middle in three evenly distributed sets (The results are shown in Table 7.), the difference is apparent.

Table 7: Number of word types in terms of their occurrence on either side of QI

\begin{tabular}{llllll}
\hline & More than 10 & $\mathbf{8 - 1 0}$ & $\mathbf{5 - 7}$ & $\mathbf{2 - 4}$ & Only once \\
\hline On the left & 7 & 8 & 12 & 57 & 72 \\
On the right & 1 & 3 & 6 & 39 & 89 \\
\hline
\end{tabular}

The results in Table 7 show that if those word types that occur only once in either side of QI are neglected, there are 84types of word that appear at least twice on the left side, while on the right side there are 49, nearly half of those on the left side. The difference is even more significant when just the first three groups of word types are taken into consideration, that is, when those word types that occur at least 5 times. There are 27 word types, each of which occurs at least 5 times on the left side of QI, while on its right side there are just 10, almost a third of the word types on the left side. These findings reveal that in the pre-Qin period QI was more likely to be collocated with words on its left side to become a fixed collocation.

On the other hand, the variety of word types that were collocated with QI on either side (156 and 138 word types separately) indicates that QI in the pre-Qin period was used very actively with other words. But the words that QI chose to be collocated with were not random, and it has its own semantic preferences. In order to investigate its semantic features, we classified the collocated words of QI on both sides with results displayed in Tables 8 and 9 . 
Table 8: Semantic preferences of QI on the left side

\begin{tabular}{|c|c|}
\hline Semantic preferences & words \\
\hline Primitive substance & $\begin{array}{l}\text { 阳,阴,精,中,神,同,道,形,元,和,金,木,水,火,土,五,一,六,四,二二十四 } \\
\text { 血,心,营 }\end{array}$ \\
\hline $\begin{array}{l}\text { Different types of QI in } \\
\text { human body }\end{array}$ & $\begin{array}{l}\text { 云,地,天,土,水,川,山,尘,寒,春,秋,暖,朝,暮,昼,夜,声,风,旱 } \\
\text { 盛德,挫微,锐,金,贵,火,清,杀,理,纯,尊严,衡,专,香,青,慜,炎,氛,柔,䒜, } \\
\text { 惠,嘉,刚,仁,丹,恶,恃,厉,陶,玉,玄 }\end{array}$ \\
\hline $\begin{array}{l}\text { Different types of QI in } \\
\text { nature }\end{array}$ & $\begin{array}{l}\text { 志,意,勇,义,正,假,民,人,魂,胎,空,尸,身,王,客,全 } \\
\text { 逆,噫,惧,郁,衰,怒,喜,欲,俯,倦,佚,辞,冯 }\end{array}$ \\
\hline Movement of QI & $\begin{array}{l}\text { 美,积,生,有,無,识,绝,合,反,冲,亡,通,用,延,顺,成,并,守,增,化,动,上, } \\
\text { 下,藏,耗,移,盖,治,平,宣,实,定,夺,吸,出,治,激,受,食,失,发,爭,利,一 } \\
\text { 鼓作,袭,偷,伤,乱,邪,断,屏 }\end{array}$ \\
\hline
\end{tabular}

Table 9: Semantic preferences of QI on the right sid

\begin{tabular}{|c|c|}
\hline $\begin{array}{c}\text { Semantic } \\
\text { preferences }\end{array}$ & words \\
\hline Movement of QI & $\begin{array}{l}\text { 胜,和,归,变,通,应,至,合,应,发,动,始,寄,去,充,发泄,且泄,分,颠,顺,震发, } \\
\text {,趣至,袭,聚,绝,缭,纵,积,畜积,流行,来,攻,夺,有生,有形,延,感应,下降,上 } \\
\text { 腾,成象,噎,易动,时发,散,敗,解,不见,不蔵, 不疠,不沈滞,不断,不调,不 } \\
\text { 慑,不悖,不安,不利,不达,不淫 }\end{array}$ \\
\hline Different types of QI & 志,意,情,息,势,色,母,机,力,焰,疾 \\
\hline Status of QI & 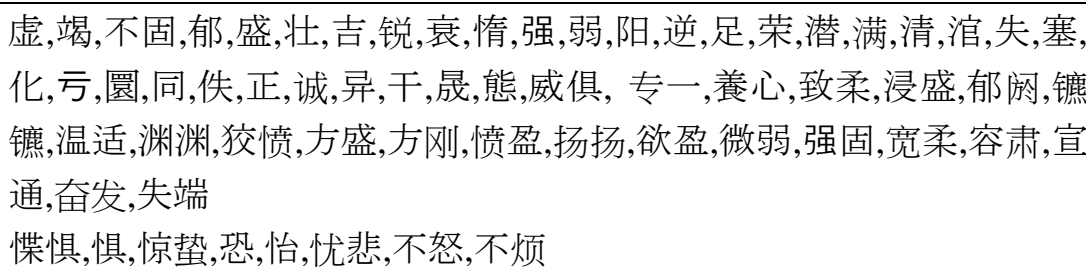 \\
\hline
\end{tabular}

Data from Table 8 reveal that in the pre-Qin period the semantic fields of the words that QI often chose on its left side were in four aspects: primitive substance, different types of QI in nature and human body, and the movement of QI. More specifically, the words that were used with QI to refer to the primitive substance reveal that in the pre-Qin period QI has already had a range of connotations as a philosophical concept, from which substantive concrete types of QI were produced to refer to the actual world and human beings. Interestingly, among the concrete types of QI, there is a number of types that can be grouped further to refer to the character and feelings of human: “志,意,勇,义, 正” to refer to human character, and “惧,郁,衰,怒,喜,欲,萝,倦,佚,辞,冯” to refer to human feelings, which provides evidence that in the pre-Qin period QI has already had abundant emotional connotations.

Data in Table 9 indicate that there are also three semantic fields that QI often chose on its right side: movement of QI, different types of QI, and status of QI. But the difference as compared with the results in Table 8 is that the words on the right side of QI were mainly of the different status after its movement, while the words on the left side were mostly of concrete types of QI. Data from both Table 8 and Table 9imply that in the pre-Qin period QI has been used far more extensively than its original meaning as "floating clouds" to refer to the substance that forms and determines the world and everything in the world, including human beings and their emotional feelings. 
Among the list of collocates in both sides of QI, what collocates have become fixed phrases? And, do they have the same meanings as those used today? Taking the phrases of QI in Han Yu Da Ci Dian as a reference, we got a list of the fixed phrases of QI that appeared in the pre-Qin period with the results displayed in Table 10:

Table 10: Fixed phrases of QI in pre-Qin period

\begin{tabular}{|c|c|c|}
\hline 阳,阴,精,中,神,形,元,和,血,心 & \multirow{4}{*}{ 气 } & \multirow{4}{*}{$\begin{array}{l}\text { 母, 色, 志, 息, 疾, 焰, 势, } \\
\text { 意, 机, 力, 情 } \\
\text { 化, 合, 和, 分, 逆, 盛, 虚, } \\
\text { 態, 绝, 塞,应, 噎, 夺,听,方 } \\
\text { 刚, }\end{array}$} \\
\hline $\begin{array}{l}\text { 云,地,天,土,水,川,山,尘,寒,暖,朝,暮,昼,夜,声,风,早,锐,贵, } \\
\text { 火,清,杀,理,纯,香,慜,炎,柔,晟,惠,嘉,刚,仁,丹,恶,恃,厉, }\end{array}$ & & \\
\hline 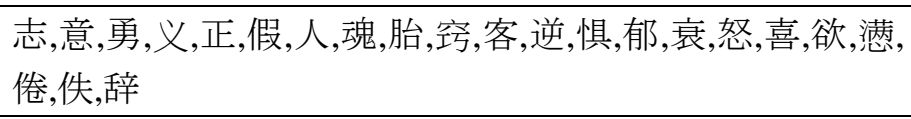 & & \\
\hline $\begin{array}{l}\text { 逆,生,有,无,绝,通,顺,化,动,上,下,耗,平,宣,夺,吸,出,治,受, } \\
\text { 失,发,爭,一鼓作,邪,断,屏 }\end{array}$ & & \\
\hline
\end{tabular}

In the first column of Table 10 are the words that are collocated with QI on its left side to become fixed phrases, and in the last column are the words on its right side. Altogether there are 122 fixed phrases of QI that were produced in the pre-Qin period, and these phrases were used both philosophically and culturally by people of that time to help understand the origins of the world and the things in the world including human beings as well. It is because of the extensive use of QI by people of the pre-Qin period that QI has since become a unique and far-reaching philosophical and cultural concept in China for people to explore and know about the world andhuman beings themselves.

But the meanings of most of these fixed phrases have been extended as time goes on. Take "diqi (地气)” as an example, this phrase in the pre-Qin period was used to refer to air arising from the earth, but now it has been extended with another character "jie(接)" connected to become another phrase to refer to life of the most ordinary people.There is a group of phrases, namely shengqi “(生气)”, youqi“(有气)”, shunqi“(顺气)”, dongqi“(动气)”, chuqi“(出气)”, faqi“(发气)”, which were used in the pre-Qin period to refer to production and movement of substance, but now these phrases are used mostly to refer to "anger". Why does QI in these phrases now just mean anger? This is a topic that deserves further in-depth study.

\section{Conclusion}

Data from the scriptures of the pre-Qin period in the CNCorpus show that QI has been extensively used by people of that time with a wide range of meanings extended from its original "floating clouds" to referring to the origins of the world and the things in the world. It is used to refer to the air, the climate, one's breath, and it is even used by the philosophers to refer philosophically to the primitive substance of the universe or even the human essence, etc. The various meanings of QI and the large collection of fixed phrases used by people of that time to explore the world laid a solid foundation for the concept of QI to become an important philosophical and cultural concept in China. The limitation of this study is that the data on which this study is based are all from the CNCorpus, which may result in the small size of data. But it is impossible for a study to cover all data because of the difficulties of collecting all the related materials. One possible compensation is to obtain and analyze sampled materials for representativeness of the subject to be studied. The materials in this study are representative as they are collected from Complete Library in Four Branches of Literature（伵库全书》）.

\section{Notes}

${ }^{1}$ See, for example, Li CunshanThe Source and Development of Chinese QI Philosophy. China Social Science Press, 1990; Liu Changlin "The Establishment of QI and Its Philosophical Values." In Philosophical Studies, no. 10, 1991, pp. 56-64.; Zhang Yuanhua "QI Theory of Pre-Qin Period and Chinese Traditional Culture." In Journal of Northwest 
University, no. 81, 1993, pp. 9-15.; "The Emerging and Development of QI Theory in Pre-Qin Period.” In Tang Du Journal, vol. 43, no. 3, 1995, pp. 1-6.;ZengZhenyu "The Philosophical Development Course of Qi." In Journal of Liaoning Normal University, no. 4, 1996, pp. 15-21.

${ }^{2}$ This version of Han Yu Da Ci Dian is the first version with 12 volumes.

${ }^{3} \mathrm{It}$ is an online corpus, and the webpage is www.cncorpus.org.

${ }^{4} \mathrm{QI}$ in Huang Di Nei Jing was not calculated and analyzed in this study for this scripture is not collected by CNCorpus.

\section{References}

Chu, Xiaoying. (2007). The Evolution of QI from Its Original Meaning to "Yiqi".Master graduate thesis, Capital Normal University.

Huang, Hongchun. (2011). On the Chinese Character QI in China's Pre-Qin Documents. Journal of Historiography, (vol. 144, no. 4), 95-98.

Li Cunshan. (1990).The Source and Development of Chinese QI Philosophy.Beijing: China Social Science Press.

Li Cunshan. (2006).Differentiation of the Meanings on Several Levels of the Concept 'Qi'.Philosophical Studies, 9, $34-41$.

Li Cunshan. (2012). QI Theory's Important Significance for Chinese Philosophy.Philosophical Studies, 3, 38-48.

Liu,Changlin. (1991). The Establishment of QI and Its Philosophical Values.Philosophical Studies, 10, 56-64.

Qu,Yinzhen. (2014). The Lexical Extensions and Their Cultural Connotations of QI in Pre-Qin Dynasties.Master graduate thesis, Nanjing Normal University.

Wan, Xianchu.(2001). Notes and Their Cultural Explanations of Shuo Wen by Zhang Tauyan.Chinese Scriptures and Cultures,1,33-40.

Wang, Lei, et al. (2012). Interdisciplinary Analysis of 'Gas Monism' from Traditional Chinese Medicine.China Journal of Chinese Medicine, (vol. 27, no. 5),573-574.

Wang, Yuxing. (1996). Gas Monism: The Philosophical Base of Traditional Chinese Medicine. Journal of Beijing University of TCM, (vol. 19, no. 3),12-15.

Yang, Xiaotong, and Yuanqian Wu.(2013). Review of 'Gas Monism'.Chinese Journal of Basic Medicine in Traditional Chinese Medicine, (vol. 19, no. 2), 130-145.

Zeng, Zhenyu. (1996). The Philosophical Development Course of Qi.Journal of Liaoning Normal University, 4, 15-21.

Zhang, Rongming. (2011). Chinese Ancient Qigong and Pre-Qin Philosophy.Shanghai: Shanghai Renmin Press.

Zhang, Yuanhua. (1993). QI Theory of Pre-Qin Period and Chinese Traditional Culture.Journal of Northwest University, 81,9-15.

Zhang, Yuanhua. (1995). The Emerging and Development of QI Theory in Pre-Qin Period. Tang Du Journal, (vol. 43, no. 3), 1-6. 